\title{
LIVROS E REVISTAS
}

UDVARDY, M. D. F., 1954. "Distribution of Appendicularians in relation to the Strait of Felle Isle. J. Fish. Res. Bd. Canada, 11 (4), p. 431-453.

As Apendiculárias mostram-se, em certas áreas, de valor, como indicadoras de massas de água. Thompson e Frost (1936) conseguiram mostrar, pela distribuição de Oikopleura vanhöffeni, a variação anual da corrente do Labrador.

UDVARDY estudou as Apendiculárias que ocorreram no plancton coletado pela expedição do "Canadian Fisheries Research Board", em agôsto e setembro de 1923, no estreito de Belle Isle (Costa canadense norte oriental). A ocorrência das espécies nas diferentes coletas permitiu concluir sôbre a origem das águas que influenciaram a régião. Das espécies, 0 . vanhöffeni, quando sòzinha, indica água fria, de origem puramente Ártica (corrente do Labrador). O. labradoriensis, sòzinha, indica águas do golfo de São Lourenço (águas do Golfo). A espécie F. borealis f. typica, muito pequena, não deu resultados homogêneos. Ocorre em tôda a área, mas apenas em águas superficiais e de mistura. A ausência de $O$. dioica indica que houve, na época, uma influência insignificante, vinda do sul. Em águas misturadas, foi comum a desintegração das Apendiculárias, em resposta às condições desfavoráveis. A ocorrência de exemplares jovens e desintegrados de $O$. vanhöffeni, auxiliou traçar a distribuição da água Ártica pura e misturada. Os resultados concordaram inteiramente com os dados hidrográficos e com a distribuição de outros grupos planctônicos. Mapas de distribuição das espécies e tabelas ilustram o trabalho.

No Brasil, onde os primeiros resultados no campo dos indicadores começam a ser obtidos, é sempre animador o sucesso alcançado em outras áreas.

I. F.

HANCOCK, D. A., 1954. "The Destruction of Oyster Spat by Urosalpinx cinerea (Say) on Essex Beds. Cons. Perm. Internat., pour l'Expl. de La Mer. Journ. du Conseil, vol. XX, n. ${ }^{\circ}$, p. 186-196, 6 figs.

Na face interna da Ilha do Cardoso, banhada pelas águas do Mar de Cananéia, existem alguns rochedos baixos, situados aproximadamente na latitude de $55^{\circ} 4^{\prime} \mathrm{S}$ e na longitude de $25^{\circ} 4^{\prime} \mathrm{W}$, sôbre os quais, muitas vêzes, efetuamos regular coleta da pequena ostra que identificamos como 
Ostrea equestris (Say) $(=0$. spreta d'Orbigny). Os moluscos mediam cêrca de $3 \mathrm{~cm}$ na carapaça ovalada, de margens crenuladas. As valvas aderentes ao substrato, com a parte interna achatada, eram de um cinzento escuro, com matizes violáceos nas bordas. Nunca observamos nesse local, conhecido pelo nome de Pereirinha, grande abundância do molusco mas, em cada viagem efetuada à Base de Pesquisas que o Instituto Oceanográfico mantém no litoral sul do E. de S. Paulo, sempre visitamos o local, antes de ganharmos a entrada da barra para sair ao mar aberto ou atingir a Ponta de Itacuruçá. Em tôdas essas ocasiões, nunca deixamos de degustar algumas dessas ostras.

Sùbitamente e depois de nos termos habituado a acompanhar, através de anos, o florescimento dêsse pequeno banco ostreícola, fomos surpreendidos pela sua extinção, sem que, para tanto, encontrássemos explicação satisfatória. Ditos rochedos achavam-se situados nas proximidades da entrada da barra, de onde os moluscos recebiam águas bem arejadas e de salinidade normal. Das indagativas efetuadas concluimos que, realmente, uma ou outra caravana de profissionais de pesca aportava periòdicamente no local. Isso, porém, vinha sendo feito durante anos seguidos sem que jamais o pequeno banco apresentasse sinais de depauperamento.

Nas várias excursões que, de passagem, efetuávamos ao local, tivemos ocasião de coletar, com certa freqüência, exemplares de Urosalpinx rushii Pilsbry, gasteropodos da família Muricidae.

Foi sòmente depois de termos lido o trabalho de HANCOCK, a respeito da ação nefasta de Urosalpinx cinerea (Say), que nos ocorreu a idéia de que, possivelmente, $U$. rushii tivesse alguma responsabilidade no empobrecimento e total destruição do diminuto banco de Ostrea equestris. Nossa convicção foi, de certo modo, reforçada pela circunstância de termos obtidos conchas de moluscos perfuradas nas dragagens efetuadas no local. Infelizmente, não nos foi possível estudar convenientemente o fenômeno, tal como foi feito pelo investigador do Fisheries Laboratory, de Burnham-on-Crouch. Dessa maneira, nossas cogitações não passam do domínio da hipótese.

Como é sabido, na América do Norte ocorrem, em grande quantidade, moluscos do gênero Urosalpinx, sobretudo do Cabo Cod à Florida, tendo-se verificado, recentemente, a sua introdução em S. Francisco. t̂les se deram bem nessa região dos Estados Unidos, onde passaram a substituir uma espécie nativa: Ocenebra erinacea.

Sabe-se que a espécie predadora alimenta-se de outros moluscos, utilizando-se da potente rádula que possui para abrir um orifício circular nas carapaças de suas presas. Por aí, introduz, o molusco, a sua probócida e, dessa maneira, retira e devora a carne da sua vítima. $O$ pesquisador CARRIKER (1943) observou que a perfuração é bem sucedida graças a um composto químico que atúa como agente suplementar da rádula.

Vários cientistas norte-americanos constataram que o molusco Urosalpinx alimenta-se de certos moluscos entre os quais figuram ostrea edulis, Mytilus edulis, Crepidula fornicata, bem como de exemplares dos gêneros Cardium e Paphia, além de não desprezarem o Balanus. 
HANCOCK, cujo trabalho inspirou êstes comentários, efetuou uma investigação muito interessante em Southward Leying, chegando à conclusão de que $73 \%$ da criação correspondente ao verão de 1953 , ficou perdida e que $58 \%$ da mesma foi desruída por Urosalpinx. Verificou mais que, em outra jazida do rio Crouch, $55 \%$ da criação foi dizimada no mesmo período, sendo que $10 \%$ das ostras de 3 anos e até mais velhas, pereceram durante a estação.

Já em 1952, KNIGHT-JONES afirmara que os moluscos pertencentes a êsse gênero constituíam sério problema para a indústria ostreícola nativa, que se achava na dependência de boas safras para a sua sobrevivência, dizendo ser uma felicidade o fato das ostras fazerem as suas posturas rio acima, onde o Urosalpinx raramente penetra devido à baixa salinidade, mas onde, por outro lado, as condições também são menos favoráveis à sobrevivência das ostras.

Parece-nos que o trabalho de HANCOCK está a sugerir uma investigação paralela, no nosso meio, onde se conta com duas espécies do gênero: $U$. rushii Pilsbry e $U$. haneti (Petit).

Enquanto isso não fôr feito, nossa hipótese a respeito da destruição da população ostreícola de Cananéia fica em suspenso.

J. P. C.

MATSUBARA, K.. 1955. "Morfologia e hierarquia", 789 p. 300 figs. Ishizaki Shoten ed., Tokio.

Nos últimos anos. vários ictiólogos japoneses têm dado publicidade a trabalhos sôbre peixes do Japão, obras que, a julgar pelo nome dos seus autores, despertariam vivo interêsse entre os especialistas europeus e americanos, não fôra o fato de o texto respectivo ser totalmente escrito em japonês. $\hat{E}$ o caso, por exemplo, dos trabalhos de YACHIRO OKADA, dos Profs. HITOAKI AIKAWA, YASUO SUYEHIRO e KIYOMATSU MATSUBARA.

Dêste último autor, professor da Universidade de Kyoto, acaba de vir a lume primoroso volume de 789 páginas que obedece ao título acima, versão aumentada e refundida que êle, de parceria com YAICHIRO OKADA, já haviam publicado, em 1938 (Toquio, edit., SANSEIDó). O novo trabalho do autor de "Bibliografia dos peixes do Japão" (1953), aparece com modificações no sistema nomenclatural, imprimidas sob a influência do trabalho de BERG (1947) "A classification of Fishes", sem dúvida alguma obra de grandes e indiscutíveis méritos, da qual já temos uma segunda edição consideràvelmente ampliada, porém desacompanhada da tradução inglêsa (Trans. Acad. Sci. U. R. S. S., vol. 20, 286 p. 263 figs. Moscow \& Leningrad, 1955). Foi aumentada a resenha bibliográfica, que conta com cuidadosas listas para cada ordem, nela tendo sido acrescentados trabalhos do após guerra.

O compêndio, fartamente ilustrado por 300 desenhos, muito dos quais relativos a detalhes anatômicos, contém quasi dez páginas consagradas a questões de morfologia, medição e caracteres merísticos, matéria in- 
dispensável à manipulagão das chaves de classificação. Cinco páginas foram reservadas aos métodos de coleta, fixaşão, conservação e rotulagem, figurando no texto elementos necessários à determinação da fauna ictiológica do Japão, seguidos de esclarecimentos e discussões úteis sôbre espécimes da Coréia, de Formosa, bem como das ilhas Curilas e Sacalina.

A única objeção séria que se poderia formular em relação ao trabalho do Prof. MATSUBARA seria talvez a referente à barreira lingüistica que nos impede de apreciar, em tôda a sua plenitude, produção de tão alta valia. $\hat{\mathbf{E}}$ de se esperar, entretanto, que de futuro, êsse impecilho seja superado e acreditamos sinceramente que isso aconteça para gáudio da Ciência. Dizemos isso porque já se anuncia, para breve, o aparecimento dos "Oceanographic Papers in Japan. Annoted Bibliography (1873-1938), laborioso trabalho a ser publicado em inglês, que ficaremos a dever à alta compreensão do Prof. KO.J HIDAKA, da Tokyo University e de seus colaboradores, iniciativa que será patrocinada pela Japanese National Commission for UNESCO.

J. P. C.

"SEA FISHERIES", their Investigation in the United Kingdom. Editado por MICHAEL GRAHAM, 487 páginas, ilustrado. Impresso por EDUARD ARNOLD (Publishers) Ltd., Londres, 1956.

O livro editado sob a supervisão de M. GRAHAM, merece ser lido por todos aquêles que direta ou indiretamente se interessam pelos problemas da pesca.

Escrito em linguagem simples e fàcilmente compreensível, abundantemente ilustrado, satisfaz plenamente a intenção do autor: "it is our intention that this book should be readable to anyone who is sufficiently interested, without special training in science or in fisheries". Ao mesmo tempo, graças ao rigor de suas afirmacões, torna-se um livro obrigatório em tôdas as bibliotecas especializadas.

Fundamentalmente, narra os trabalhos executados pelos laboratórios de pesca do Reino Unido. Os capítulos que o compõem são assinados por cientistas já bastante conhecidos por seus trabalhos anteriores. A seqüência dos assuntos demonstra o cuidado havido em sua preparação, visivel nestas palavras: "No book on fishery science could be understood, still less appreciated, without some knowledge of the fisheries themselves, and this book therefore begins with a description of the commercial fisheries".

É-nos impossível, aqui, analisar detalhadamente todos os seus capítulos. A importância dos assuntos tratados pode ser julgada pela seguinte relação: I - Science and the British Fisheries, M. Graham; II - Fisheries of the United Kingdom, H. Wood; III - Plankton and Basic Production, C. E. Lucas; IV - Plankton and Fisheries Biology, C. E. Lucas; V - Benthos and Shellfish of Commerce, H. A. Cole; 
VI - The Pelagic Phase, A. C. Simpson; VII - The Cod, Haddock and Hake, B. B. Parrish; VIII - Plaice, M. Graham; IX - The Theory of Fishing, R. J. H. Beverton; $\mathrm{X}-$ Synopsis and Commentary, M. Graham.

No Capítulo III, analisa os dois grandes grupos planctônicos, os fatôres que determinam sua abundância, o papel de algumas espécies na caracterização das condições hidrográficas e na alimentação dos animais, os principais aparelhos para a coleta de mostras quantitativa e qualitativa, etc.

O Capítulo $\mathbf{V}$, trata dos diferentes aparelhos de coleta de material bentônico, analisa as diversas comunidades bentônicas de Petersen em águas dinamarquesas, bem como tece consideracões sôbre o valor de pesquisas dessa natureza. Afirma que o estudo da produtividade bentônica, apesar da sua complexidade, quando bem conduzido, poderá fornecer as "basic causes of fluctuation in the production of demersal fish". Descreve a distribuição, métodos de pesca, migracões e cultura das principais esrécies de ostras, lagostas, caranguejos, camarões, etc, acompanhados de tabelas estatísticas e mapas de distribuição.

Os três últimos capítulos dêsse livro são extremamente interessantes. A pesca, por meio do "otter trawl", conduz a um rápido depauperamento dos fundos. Regiões submetidas a explorações intensivas e contínuas, cedo apresentam sinais de sobrepesca: "the classical problem of fishery research".

O mar do Norte é a principal área de pesca da Inglaterra. Antes da Segunda Grande Guerra, a sua produtividade tinha atingido tão baixos níveis devido à sobrepesca, a ponto de ocasionar preocupações gerais. M. Graham e equipe cientifica, tomaram a si a solução do caso: manter em nível econômico os estoques intensamente explorados. Tarefa complexa e gigantesca. Entretanto, decorridos agora alguns anos, estão aptcs a dizer: "Finally, we believe, we shall be able to show that all the essential factors in this problem are now understood, to this extent, that they have been estimated from sufficient data for a first approximation, and even for a second approximation in certain respects".

Nestes capitulos, com abundância de detalhes e ilustrações, são discutidos os diferentes aspectos que o problema envolve: evidência de declínio, intensidade de exploração, mortalidade natural e mortalidade provocada pela pesca, ao mesmo tempo que é descrita a biologia das principais espécies comerciais: bacalhau, "haddock", merluza e linguado.

No capítulo IX, são discutidos matemàticamente pontos extremamente importantes como: mortalidade total, métodos de regulamentação da pesca, mortalidade natural, etc..

Excelente resenha bibliográfica acompanha a obra.

P. S. M. 
HARTMANN, G., 1956. "Weitere neue marine Ostracoden aus Brasilien. Beitrage sur neotropischen fauna, I (1), p. 19-62.

Por ocasião de proveitosa excursão científica realizada ao nosso País, em meados de 1952, o sr. Prof. Dr. A. REMANE, do Institut für Meereskunde, de Kiel (Alemanha), efetuou estudos sôbre matéria de sua especialidade: os Trochelminthes. Além disso, coletou amostras de outros grupos, entre êles, o dos Ostracoda, que foi entregue à competência do Dr. G. HARTMANN, especialista de renome internacional. Dai resultou o aparecimento do trabalho a que nos referimos nestas apreciacõos, em que se descreve um gênero novo (Mesocythere) e 11 espécies novas: Leptocythere ornata, L. costata, Mesocythere foveata, $M$. alongata, M. punctata, Elofsonella (Cythereis) alata, Cytherura cancellata, Loxoconcha foveata, Sclerochiles ventriosus, Paradoxostoma fornicatum e $P$. ilhabelae. O material foi muito bem estudado e apresentado através de descrições minuciosas, acompanhadas de desenhos elucidativos. Foi assinalada a composição, em Ostracoda, de cada amostra, indicando-se o local da coleta e a natureza do substrato correspondente.

Muito pouco se sabe a respeito dos Ostracoides do Brasil, apesar de não serem êles raros, quer nas amostras planctônicas de água doce, salobra ou salgada, quer nos sedimentos bentônicos da costa e até mesmo em certos trechos das nossas praias. Mais do que isso, é de se lamentar que o próprio material sulamericano seja insuficientemente conhecido, apesar do grupo oferecer, sob o ponto de vista cientifico e até econômico, campo promissor para a efetivação de interessantes estudos.

Vale a pena fazer algumas consideracões gerais sôbre grupo tão interessante, para o qual, segundo nos consta, não existem ainda especialistas no Brasil.

Refere Douglas, no seu livro "The Study of the Oceans" (pg. 150), não serem ainda conhecidos "os machos de certas espécies", pois, como se sabe, a maioria dos representantes do grupo é constituída por indivíduos unisexuados, havendo porém exceções. Quanto ao valor econômico, Welch (1935), na sua "Limnology" (pg. 206), considera os Obstracoda (juntamente com os Cladocera e os Copepoda), como "dos mais importantes e significativos". Sob o ponto de vista puramente científico, não se deve perder de vista, por exemplo, as curiosas pesquisas de Haneda, Kuriza e Nakamura, sôbre fenômenos de luminescência, sobretudo em relação aos representantes do gênero Cypridina. Harvey (1952), no seu interessante livro "Bioluminescence", cita o caso transcorrido durante a Segunda Grande Guerra, em que foram aproveitados componentes dêsse gênero para a produção de luz. Conta-nos êle como oficiais da marinha nipônica se utilizaram de animais secos, obtendo, assim, fontes luminosas de baixa intensidade. Em virtude de se acharem muito próximos do inimigo e na impossibilidade de se servirem de lanternas elétricas, valeram-se do pó de Cypridina, colocado em meio úmido na palma da mão, para a leitura de mensagens. A este fato, reporta-se também Johnson (1955) no seu trabalho "The luminescence of Biological Systems" (pg. 357). 
Algumas espécies de Ostracoda têm uma distribuição muito vasta. Lombard (1956), na sua "Geologie Sedimentaire" (pg. 152), cita o caso de Pseudocythere caudata, que vive atualmente ao longo das costas da Noruega, a $75 \mathrm{~m}$ de profundidade, encontrando-se também ao largo de Buenos Aires, em fundos de $3.480 \mathrm{~m}$. Por outro lado, Macrocypris minna, ocorre entre 35 e $550 \mathrm{~m}$, na costa norueguesa e entre 640 e $1.350 \mathrm{~m}$ ao longo da costa marroquina.

O trabalho do Dr. HARTMANN parece-nos fixar um ponto de partida, dos mais auspiciosos, para o estudo acurado de um grupo que, incontestàvelmente, merece ser devidamente considerado, sobretudo por parte dos encarregados da investigação relacionada com a biologia da pesca. Já é tempo de se estudar, com exatidão, a produtividade de cada biótopo em que se alimentam organismos marinhos, especialmente peixes, moluscos e crustáceos. $\hat{E}$ de se esperar, portanto, que êsse trabalho contribua poderosamente para o inicio de novas e promissoras pesquisas.

J. P. C.

JOSEPH, F. B., \& YERGER, R. W., 1956. The fishes of Alligator Harbor, Florida, with notes on their natural history. Papers from the Oceanographic Institute. Contributión n. ${ }^{9}$ 7, p. 11-156. Florida State University.

A fauna marinha da região da Flórida, conta entre os seus principais investigadores, com os nomes de Evermann \& Kendall (1900), Ginsburg (1929, 1950, 1951, 1952 e 1953), Gunter (1945) e Reid (1954). Mais recentemente, JosEPH \& YERGER, deliberaram proceder a novas pesquisas, com o objetivo de completar a matéria já constante de trabalhos fundamentais sôbre a região, enriquecendo assim a literatura especializada com novas informações e dados interessantes, obtidas em um período superior a quatro anos, compreendido entre maio de 1950 e novembro de 1954. Dessa maneira, foram estudadas 121 espécies de peixes, pertencentes a 95 gêneros e 55 famílias.

Conforme se vê pelo título do trabalho, o estudo foi levado a efeito no Alligator Harbor, situado aproximadamente a 40 milhas a SSW de Tallahasse, Flórida, na latitude de $29^{\circ} 55^{\prime} \mathrm{N}$ e longitude de $84^{\circ} 25^{\prime} \mathrm{W}$. Nesse trabalho, existe matéria de interêsse para os ictiólogos brasileiros, visto como $\mathrm{um}$ pouco mais de $60 \%$ dos peixes investigados pelos autores, freqüenta também a costa do Brasil. As anotações são, por vêzes, interessantíssimas, sugerindo confrontos oportunos com o que ocorre nas nossas águas territoriais, pelo que vamos citar alguns rápidos exemplos.

Referindo-se à Arraia borboleta - Gymnura micrura (Bloch \& Schneider), da qual o Instituto Oceanográfico possui um macho e uma fêmea, ambos jovens, provenientes do Norte do Brasil $\left(2^{\circ} 58^{\prime} \mathrm{N}-49^{\circ} 44^{\prime}\right.$ W), dizem: "Smith (1907) assinala que o número habitual de embriões é de dois. Uma das fêmeas prenhes que examinamos, exibia oito e outra seis". Comparando a Tainha - Mugil cephalus L., com a Paratí 
- Mugil curema Cuv., \& Val., dizem que embora na aparência a prímeira divirja pouco da segunda, "há uma grande diferença em certos aspectos da sua biologia". Referem-se também às épocas de desova das duas espécies e à importância econômica por ambas representadas. Em relação a outras espécies, são feitas observações muito oportunas quanto ao habitat ou ao porte dos individuos, sendo de se lamentar, apenas, o fato de, na maioria das referências, os dados serem transmitidos com uma certa parcimônia.

O trabalho dos autores, enquadra-se perfeitamente dentro das recomendações dos membros da Seção Zoológica da União Internacional de Ciências Biológicas, reunidos recentemente na Estação de Roscoff para discutir problemas relativos ao estudo comparativo da Biologia Marinha. De fato, sob os auspícios dos Profs. P. Drach, L. Fage e G. Teissier, com a participação do Prof. S. O. Hörstadius, presidente da U. I. C. B., o conclave transcorreu com pleno êxito e contou com a participas̃ão de biologistas de 14 países. Nêle, foi aprovada uma resolução exaltando o valor da investigação biológica das espécies marinhas, tendo sido salientada a importância da publicação de listas de componentes da fauna e da flora marinhas.

O trabalho de JOSEPH \& YERGER, acha-se muito ligado à nossa fauna de água salgada, motivo pelo qual não deve escapar à atenģ̃o de nenhum ictiólogo brasileiro.

J. P. C.

ALLAN, J., 1956. “Cowry Shells of World Seas", $\mathrm{X}+170$ pp. Georgen House, Melburne. Australia.

Os Búzios foram sempre objeto de admiração e procura, em tôdas as partes do mundo, quer pela beleza de seu colorido, quer pelas suas formas bizarras. São, em geral, vistosos e atraentes; alguns exibem tamanho apreciável, sendo outros ricamente ornamentados. Pode-se citar, como exemplo, o gênero Cypraca, do qual Weinkauff relaciona cêrca de 190 espécies vivas e 97 fósseis.

Sôbre o desenvolvimento de algumas formas, há ainda sérias divergências, havendo outras mais ou menos bem conhecidas cujo porte é submetido a grandes variações, oscilações essas consideradas como individuais, por muitos autores. Quase todos foram ou continuam a ser empregados como objeto de adôrno pessoal, por tribos selvagens ou semi-selvagens. Mesmo entre os povos civilizados, idêntica prática persiste, sendo freqüente a utilização dos Búzios ora como enfeite ou adôrno caseiro, ora como engaste de caixas de jóias, braceletes, broches ou conservados simplesmente como "souvenirs".

Ao que se sabe, não foi ainda esboçado nenhum trabalho sôbre os Búzios da nossa costa, pôsto que, a respeito do assunto, houvesse matéria a ser explorada, desde a própria beleza do molusco, em si, até o seu 
emprêgo pelos pescadores para assinalar a aproximação de cardumes de peixes.

Búzio ou Buzo (na Bahia) é assim definido no Dicionário de R. von Ihering: "Molusco do mar, de concha retorcida em forma de corneta e da qual os pescadores do mar se utilizam para dar sinais, (buzina; buccinum do latim). São Gasteropodes prosobranchios da fam. Strombideos (sic) (Gen. Strombus). A denominação indígena correspondente é "Atapú".

Como todos sabem, à leste da I. de S. Sebastião, no litoral bandeirante, existe uma ilha aparentemente dividida em duas, a que se dá o nome de Ilha dos Búzios. Querem alguns relacionar tal nome ao fato de aí ter existido muito "búzio". A denominação, entretanto, é definida na obra póstuma do Dr. João Mendes de Almeida, de maneira diversa. Refere o autor do "Dicionário Geographico da Província de S. Paulo" (1902) que o nome vem de Bu-bo, isto é, "saídas debaixo d'água" ou "surgidas do mar", esclarecendo: "Os portuguêses, ouvindo o som da palavra, pensaram ser buzios, esquecendo-se de que buzio é de origem africana". Diz mais que alguns escrevem ainda com maior corrupģa Búgios, porque os africanos pronunciam bújüs, concluindo: "Com effeito, estes ilhéos, de tão razos, são vistos no meio das ondas como surgindo do mergulho, a proporsão que o navegante aproxima-se de cada um" (pg. 43).

O curioso é que êsses Búzios, representados por carapaças de Strombus, Cypraea, Buccinum ou Cassis, são assim chamados não sòmente no nosso País, mas também em Portugal onde se dá a denominação Buzina, a componentes do gênero Tryton.

Estas consideracõos foram inspiradas no trabalho de JOYCE ALLAN, no qual o autor reuniu, em volume de 170 páginas, ilustrado por 15 estampas, os Búzios de diversas regiões do Globo, lindos espécimes das águas tropicais e subtropicais.

No capitulo introdutório, figuram informações gerais sôbre a biologia e o sistema nomenclatural dos Búzios, existindo, para cada espécie, indicações quanto ao porte, colorido e demais características indispensáveis à tarefa de determinação especifica.

Há, no trabalho de ALLEN, um ponto passivel de crítica, qual seja o de ter sido cuidada, apenas, a parte conchiliológica, sem ser dada a devida atenção à pròpriamente malacológica, critério êsse que, em nossos dias, já está superado. Embora não se possa deixar de lamentar tal procedimento, é de se reconhecer o considerável esfôrço dispendido por ALLEN, no sentido de apresentar um livro sem dúvida alguma interessante e que deve figurar na biblioteca de quantos se dedicam aos estudos relacionados com os moluscos.

J. P. C. 
HAIG, J., 1956. "The Galatheidae (Crustacea Anomura) of the Allan Hancock Atlantic Expedition with a review of the Porcellanidae of the Western North Atlantic. Allan Haneock Atlantic Expedition. Report n.9 8, p. 1-43, pl. I. The Univ. of South California Press.

JANET HAIG, cujo consciencioso trabalho sôbre os Crustáceos Anomuros do Chile (1955) já nos impressionara favoràvelmente, examina, na publicação que passamos a comentar, três espécies da família Galatheidae e 23 da fam. Porcellanidae, tôdas provenientes das coletas do barco Valero III, por ocasião de um cruzeiro feito ao Mar das Caraíbas, em abril de 1939 .

Essa publicagão sôbre os Anomura do Atlântico Norte ocidental, interessa aos nossos carcinólogos, sobretudo porque, infelizmente, muito pouca coisa se tem dado a lume a respeito do Grupo, após os estudos de Carlos Moreira e em virtude do fato de que cêrca de $27 \%$ das espécies referidas por HAIG, encontram-se também na costa do Nordeste e até no Sul do Brasil. Tôdas fazem parte da fam. Porcellanidae, sôbre a qual já Fenner Chace (1942) havia demonstrado a necessidade de se fazer uma revisão geral, baseada em exemplares de tôdas as partes do mundo. De fato, comprovou-se mais uma vez que o gênero Pisosoma Stimpson, 1858 não representava grupo bem definido, nêle havendo várias espécies com caracteres do gênero Pachycheles. Tanto isso é exato que HAIG, examinando a espécie considerada por Moreira (1920) como Pisosoma risei e comparando-a com farto material existente no Museu Nacional dos Estados Unidos, chegou à conclusão de que ela realmente pertence ao gênero Pachycheles, propondo assim a nova combinação Pachycheles riisei (Stimpson) para designá-la.

No trabalho em questão, figura ainda Pachycheles monilifer (Dana), habitante do R. de Janeiro, da Bahia e de Pernambuco. Nêle vamos encontrar Petrolisthes armatus (Gibbes), do R. de Janeiro, que a autora parece considerar idêntica a $P$. iheringi Ortmann, de S. Sebastião, no E. de S. Paulo. Figuram, também, P. galathinus (Bosc), da Ilha da Trindade, dos Estados de Alagoas e Pernambuco, bem como $P$. amoenus (Guérin), do R. de Janeiro, de Santa Catarina e que Rathbun obteve no rio Paraíba. Finalmente, nos defrontamos com Porcellanopsis rosea (Rathbun), nova combinasão, de Pernambuco (Ilha do Nogueira), espécie que ainda não havia sido assinalada no Atlântico Norte.

O trabalho, cujo texto contém informações básicas para os carcinólogos brasileiros, acha-se ilustrado por excelente estampa de uma espécie nova do Panamá, sendo dotado de resenha bibliográfica muito útil e bem compilada.

J. P. C. 